Volume 3, Number 2, Agustus 2020

p-ISSN: 2615-0212 | e-ISSN: 2621-2838

https://ejournal.iaifa.ac.id/index.php/dirasah

\begin{tabular}{|c|c|c|}
\hline Accepted: & Revised: & Published: \\
April 2020 & Mei 2020 & Agustus 2020 \\
\hline
\end{tabular}

\title{
Kepemimpinan Karismatik Kiai dalam Membangun Budaya Organisasi diPesantren Salafiyah
}

\author{
Muhamad Matin Shopwan Amarullah \\ UIN Sunan Gunung Djati Bandung, Indonesia \\ e-mail:shopwan90@gmail.com \\ Mulyani \\ UIN Sunan Gunung Djati Bandung, Indonesia \\ e-mail:mulyanimulyani113@gmail.com \\ Ari Prayoga \\ UIN Sunan Gunung Djati Bandung, Indonesia \\ e-mail:ariprayoga@madrasah.id
}

\begin{abstract}
The purpose of this study is to uncover and analyze the forms of organizational culture in the Salafiyah Al-Jawahir Islamic Boarding School as the implication of the role of the kiai's charismatic leadership in the pesantren. This research uses a phenomenological approach with qualitative research methods. Data collection techniques in this study used interview, observation, and documentary study techniques. As for the technique of determining data sources using purposive sampling. The results showed that charismatic kiai had a strategic role in efforts to develop organizational culture in pesantren. Organizational culture in the Salafiyah AlJawahir Islamic Boarding School is implemented through santri activities which include; first, daily activities, namely congregational prayers, Nahwu-Sharaf learning, and learning to read and memorize the Qur'an; second, weekly activities, namely the reading of the book Al-Barzanji, blessings, recitation of yasin, and reading of manakibs, the study of the Ta'lim Al-Muta'allim and the Wasiat Al-Mustafa, learning of Qur'anic recitation, muhadarah, reading alms, and recitation for alumni; third, annual activities, which commemorate the Birthday of the Prophet Muhammad SAW, commemorate the Mi'raj of the Prophet Muhammad SAW, a pilgrimage to the tomb of
\end{abstract}


Walisongo, the hijri new year, and Eid al-Adha. Apart from these activities, organizational culture is also applied in the life of pesantren through the establishment of an organizational structure managed by santri.

Keywords: Organizational culture; the charismatic leadership of the kiai; salafiyah boarding school

\begin{abstract}
Abstaksi
Tujuan penelitian ini yaitu untuk mengungkap dan menganalisis bentuk budaya organisasi di Pondok Pesantren Salafiyah Al-Jawahir sebagai implikasi dari peran kepemimpinan karismatik kiai di pesantren tersebut.Penelitian ini menggunakan pendekatan fenomenologis dengan metode penelitian kualitatif. Teknik pengumpulan data dalam penelitian ini menggunakan teknik wawancara, observasi, dan studi dokumenter. Sedangkan untuk teknik penentuan sumber data menggunakan sampling purposive. Hasil penelitian menunjukkan bahwa kiai karismatik memiliki peran strategis dalam upaya mengembangkan budaya organisasi di pesantren. Budaya organisasi di Pondok Pesantren Salafiyah Al-Jawahir diterapkan melalui kegiatan santri yang meliputi; pertama, kegiatan harian, yaitu shalat berjamaah, pembelajaran Nahwu-Sharaf, dan pembelajaran membaca dan menghafal Al-Qur'an; kedua, kegiatan mingguan, yaitu pembacaan kitab Al-Barzanji, shalawat, pembacaan yasin, dan pembacaan manakib, pengajian kitab Ta'lim Al-Muta'allim dan WasiatAlMustafa, pembelajaran tilawat Alquran, muhadarah, pembacaan istigasah, dan pengajian untuk alumni; ketiga, kegiatan tahunan, yaitu memperingati Maulid Nabi Muhammad SAW, memperingati Isra Mi'raj Nabi Muhammad SAW, ziarah ke makam Walisongo, tahun baru hijriah, dan Idul Adha. Selain melalui kegiatan tersebut, budaya organisasi juga diterapkan dalam kehidupan pesantren melalui pendirian struktur organisasi yang dikelola oleh santri.
\end{abstract}

Kata Kunci: Budaya organisasi; kepemimpinan karismatik kiai; pesantren salafiyah.

\title{
Pendahuluan
}

Pendidikan Islam di Indonesia memiliki tiga jalur institusional utama, yaitu: 1) pengajian Qur'an, yaitu instruksi dasar dalam belajar membaca dan melafalkan tanpa memahami Al-Qur'an secara harfiah; 2) pembelajaran di pesantren atau pondok, yaitu pesantren untuk siswa dengan fasilitas menengah atau lanjutan dalam tradisi pengetahuan Islam; dan 3) pembelajaran di madrasah, yaitu sekolah modern di Indonesia yang menggunakan kelas berjenjang, buku pelajaran, dan guru yang digaji untuk memberikan campuran pendidikan agama dan umum ${ }^{1}$.

Di antara ketiga jenis pendidikan Islam tersebut, pesantren adalah bentuk sekolah Islam tertua di Indonesia. Sebagai jenis sekolah Islam yang paling tradisional, kebanyakan pesantren melayani anak-anak dari daerah pedesaan. Pesantren adalah

${ }^{1}$ Robert W. Hefner, ed., Making Modern Muslims: The Politics of Islamic Education in Southeast Asia (Honolulu: University of Hawai'i Press, 2009).

Dirasah, Vol. 3, No.2, Agustus 2020 
benteng pengetahuan Islam dan pencetak utama ulama dan guru Islam. Mereka fokus pada transmisi ilmu-ilmu Islam klasik, termasuk studi tentang Al-Qur'an dan hadits, yurisprudensi, Tata bahasa Arab, mistisisme (tasawwuf), dan ilmu-ilmu Arab (alat). Secara tradisional, siswa pesantren belajar tentang uraian-uraian Islam klasik, yang dikenal sebagai kitab kuning².

Hal yang paling identik dengan pesantren adalah adanya figur kiaiyang menjadi pemimpin sekaligus penggerak roda pengelolaan pendidikan di pesantren. Suatu lembaga tidak bisa disebut pesantren apabila pada lembaga tersebut tidak ada figur kiai.Kiaiadalah elemen yang paling penting di pesantren, atau bisa disebut juga sebagai pendiri pesantren. Pertumbuhan alami pesantren bergantung langsung pada kompetensi pribadi kiai ${ }^{3}$.

Dhofier mengungkapkan bahwa secara tradisional, istilah Kiai mengacu pada tiga gelar yang berbeda: 1) gelar pemujaan untuk hal-hal suci; misalnya, "Kiai Garuda Kencana" yang mengacu pada Pelatih Emas di Pengadilan Yogyakarta; 2) gelar pemujaan bagi orang tua pada umumnya; 3) gelar yang diberikan oleh komunitas kepada seorang cendekiawan Muslim yang memiliki pesantren dan mengajarkan teks-teks Islam klasik kepada murid-muridnya. Sebagai seorang cendekiawan Muslim yang memiliki pengetahuan mendalam tentang Islam, ia berhak untuk mendapatkan gelar Ulama ${ }^{4}$.

Sebagian besar kiai memiliki pesantren mereka sendiri yang berfungsi sebagai pangkalan utama untuk pengajaran keagamaannya ${ }^{5}$. Kiaimerupakan figur sentral dalam dunia pesantren dan juga faktor determinan terhadap maju dan mundurnya sebuah pondok pesantren termasuk pendidikan dan sistem kurikulumnya, bahkan ada pesantren yang tidak menerapkan sistem kurikulum,namun hal tersebut merupakan hak prerogatif kiai ${ }^{6}$.Menurut Muflichah kiaimemiliki posisi sebagai pengawas muridnya dalam segala hal, yang pada akhirnya berperan sebagai peneliti dan penyaring aspek budaya dari luar, dalam keadaan seperti itu kiai berperan sebagai agen budaya ${ }^{7}$.

${ }^{2}$ Charlene Tan, Islamic Education and Indoctrination: The Case in Indonesia (New York: Routledge, 2011).

${ }^{3}$ Zamakhsyari Dhofier, "THE PESANTREN TRADITION: A Study of the Role of the Kyai in the Maintenance of the Traditional Ideology of Islam in Java" (THE AUSTRALIAN NATIONAL UNIVERSITY, 1998).

${ }^{4}$ Dhofier.

${ }^{5}$ Ferry Muhammadsyah Siregar, Nur Kholis Setiawan, and Robert Setio, "Religious Leader and Charismatic Leadership in Indonesia: The Role of Kyai in Pesantren in Java," Kawistara 3, no. 2 (2013): 117-226.

${ }^{6}$ Mansur Hidayat, "Model Komunikasi Kyai Dengan Santri Di Pesantren," Jurnal ASPIKOM 2, no. 6 (2017): 385, https://doi.org/10.24329/aspikom.v2i6.89.

${ }^{7}$ Siti Muflichah, "The Charisma Leadership Style of Kyai Haji Arwani Amin The Founder of Yanbuul Quran Pesantren, Kudus," Journal of Islamic Civilization in Southeast 03, no. 01 (2014): 61-81, https://doi.org/10.24252/JICSA.V3I1.774. 
Kepemimpinan kiaidi pesantren merupakan hal yang sangat strategis. Implementasi kepemimpinan tersebut melibatkan ruang untuk pengambilan keputusan dan tindakan yang berpengaruh, baik secara langsung maupun tidak langsung melalui inisiasi tindakan dan peristiwa terhadap pihak lain. Apa yang diputuskan dan dilakukan oleh para pemimpin tersebut, ketika diperluas oleh konteks organisasi yang besar, maka keputusan dan tindakan tersebut dapat memiliki konsekuensi yang luas pula bagi pihak lain ${ }^{8}$.

Selain itu, karakter seorang kiaijuga sangat berpengaruh dalam meningkatkan harga diri pesantren di mata masyarakat pada umumnya. Karisma seorang kiaiberkontribusi untuk "memikat energi" ke dalam pesantren. Peran kiaisebagai pemimpin yang karismatik dipandang sebagai seseorang yang memiliki visi atau tujuan yang memikat, kemampuan untuk mengkomunikasikan visi tersebut secara efektif, kemampuan untuk memotivasi orang lain untuk bergabung dengannya,konsisten dan terfokus, sangat percaya diri, dan memahami apa yang diperlukan untuk menyelesaikan misi ${ }^{9}$.

Seorang pemimpin karismatik yang berkualitas memiliki indikator tertentu, yaitu: 1) memiliki kemampuan untuk mengartikulasikan visi masa depan ideal yang jauh lebih baik daripada saat ini; 2) dapat mengkomunikasikan ide dan tujuan yang kompleks dengan cara yang jelas dan menarik, sehingga semua orang dari tingkat manajemen puncak hingga tingkat bawah organisasi dapat memahami dan mengidentifikasinya; 3) membangun kepercayaan pada pengikutnya melalui keyakinan diri yang tak tergoyahkan, kepercayaan yang teguh, keyakinan moral yang kuat, dan optimisme; 4) memiliki kemampuan untuk menginspirasi pengikutnya; 5) bersedia menanggung resiko pribadi yang besar demi mendapatkan kepercayaan dari pengikutnya; 6) bersifat energik dan berfungsi sebagai role model untuk menyelesaikan sesuatu secara tepat waktu; 7) melibatkan hubungan atau interaksi dengan pengikutnya; 8) mampu meminimalisir konflik internal; 9) memberdayakan pengikutnya dengan sistemrole model dan pembinaan, memberikan umpan balik dan dorongan, dan membujuk pengikutnya untuk mengambil lebih banyak tanggung jawab agar keterampilan dan kepercayaan diri mereka tumbuh; 10) sering mempromosikan diri dan visi mereka ${ }^{10}$.

Selain itu, Kessler mengungkapkan bahwa terdapat beberapa perilaku dan kompetensi utama yang dimiliki oleh para pemimpin karismatik. Pertama, mereka dapat menggambarkan visi masa depan yang jelas dan menarik untuk ditempatkan ke

${ }^{8}$ P.A.Duignan and R.J.S.Macpherson, eds., Educative Leadership: A Practical Theory for New Administrators and Managers (Bristol: The Falmer Press, Taylor \& Francis Inc., 2004).

${ }^{9}$ Robert N. Lussier and Christopher F. Achua, LEADERSHIP Theory, Application, \& Skill Development, 4th ed. (OH: Cengage Learning, 2010).

${ }^{10}$ Lussier and Achua.

Dirasah, Vol. 3, No.2, Agustus 2020 
dalam organisasi mereka. Kedua, mereka mempersonalisasi visi dengan memberikan harapan dengan perilaku yang tepat untuk pengikutnya serta mengungkapkan keyakinan bahwa mereka dapat berhasil. Ketiga, pemimpin yang karismatik berperan sebagai teladan sehingga mendapatkan respek dari pengikutnya.Keempat, mereka tidak takut untuk keluar dari tradisi, berani untuk mengambil tanggung jawab demi membangun tujuan yang diinginkan. Tindakan ini ditunjukkan untuk menginspirasi pengikutnya dan meningkatkan kesuksesan dan kepuasan bagi mereka ${ }^{11}$.

Seorang kiaiyang memimpin pesantren tentu memiliki strategi dalam mengembangkan budaya organisasi di pesantrennya.Hiebert \& Klatt menekankan tentang pentingnya memahami budaya organisasi, hal ini disebabkan karena beberapa faktor, yaitu: 1) budaya sebagian besar tidak terlihat oleh orang-orang yang di dalamnya; 2) budaya sangat sulit diubah; 3 ) tidak memahami budaya organisasi sendiri dapat menjadi bencana bagi keberhasilan organisasi tersebut dan kehancuran bagi pengikutnya yang mewakili organisasi tersebut; 4) organisasi menjadi semakin beragam, jika keragaman menjadi sumber peningkatan efektivitas, budaya organisasi saat ini harus dipersiapkan; 5) banyak proses merger organisasi atau pengambilalihan organisasi yang tampak hebat dilihat dari sudut pandang finansial dan aset, namun menjadi bencana ketika budaya organisasi tidak dapat digabungkan dengan mudah ${ }^{12}$.

Strategi yang dipilih oleh pemimpin akan menghasilkan perubahan dalam budaya organisasi serta akan menimbulkan konsekuensi bagi setiap individu dalam hal tingkat batasan yang dikenakan atau otonomi yang diberikan. menyatakan bahwa kepemimpinan karismatik memiliki pengaruh yang kuat terhadap komitmen organisasi.Kekuatan para pemimpin karismatik terletak pada kemampuan mereka untuk membentuk hubungan baik dengan orang lain dengan menyediakan apa yang diinginkan pada saat itu.Salah satu pesantren yang dikelola oleh kiaikarismatik dapat ditemukan dikabupaten Bandung, Jawa Barat ${ }^{13}$.

Karismatik kiaiPondok Pesantren Salafiyah Al-Jawahir kabupaten Bandungsangat berpengaruh bagi santri dan masyarakat sekitarnya karena perannya sebagai model dan kepribadian yang dapat dipercaya. Kiai menjadi pemimpin umat dan legitimasi bagi masyarakat dengan mengambil dasar pijakan agama dalam melakukan tindakannya sehingga masyarakat hanya mendengarkan dan mematuhinya ketika kiaimengatakan sesuatu. Sebagaimana dinyatakanSukamto bahwa melalui

${ }^{11}$ Eric H. Kessler, Management Theory in Action: Real-World Lessons for Walking the Talk (New York: PALGRAVE MACMILLAN, 2010).

12 Murray Hiebert and Bruce Klatt, The Encyclopedia of Leadership: S Practical Guide to Popular Leadership Theories and Techniques (New York: McGraw-Hill, 2001).

13 Marie H. Kavanagh and Neal M. Ashkanasy, "The Impact of Leadership and Change Management Strategy on Organizational Culture and Individual Acceptance of Change during a Merger," British Journal of Management 17, no. SUPPL. 1 (2006), https://doi.org/10.1111/j.1467-8551.2006.00480.x. 
karisma yang melekat padanya, kiaidijadikan imam di bidang ubudiyyah dan sering diminta untuk memecahkan masalah yang menimpa masyarakat. Rutinitas ini semakin memperkuat peran kiaidi masyarakat karena kehadirannya dipercaya untuk memberi berkah $^{14}$.

Berdasarkan uraian di atas, penelitian ini bermaksud untuk menguji bagaimana kepemimpinan karismatik kiaidalam membangun budaya organisasi yang telah dibentuk di Pondok Pesantren Salafiyah Al-Jawahir.Tujuan penelitian ini adalah untuk menganalisis peran kepemimpinan karismatik kiai dalam membangun budaya organisasi yang telah dibentuk di Pondok Pesantren Salafiyah Al-Jawahir.

\section{Metode Penelitian}

Pendekatan dalam penelitian ini menggunakan pendekatan fenomenologis dan system approach. Metode penelitian menggunakan metode kualitatif-deskriptif yang dilakukan terhadap suatu kesatuan sistem berupa program, kegiatan, peristiwa, atau sekelompok individu yang terikat oleh tempat, waktu, atau ikatan tertentu ${ }^{15}$. Persiapan untuk pendekatan ini dilakukan dengan menyiapkan kerangka penelitian yang berisi fokus penelitian, metode pengumpulan data yang digunakan, dan para peserta yang terlibat ${ }^{16}$.Penelitian ini dilaksanakan di Pondok Pesantren Salafiyah Al-Jawahir Soreang, kabupaten Bandung.

Teknik pengumpulan data menggunakan teknik wawancara, observasi, dan studi dokumenter. Teknik penentuan sumber data menggunakan sampling purposive yang dilakukan dengan mengambil orang-orang terpilih betul oleh peneliti menurut ciri-ciri spesifik yang dimiliki oleh sampel itu ${ }^{17}$.Fokus penelitian ini adalah kepemimpinan karismatik Kiai dalam membangun budaya organisasi pesantren di Pondok Pesantren Salafiyah Al-Jawahir Soreang, kabupaten Bandung. Penelitian ini dilakukan melalui dua tahap, yaitu: 1) pengumpulan data melalui observasi partisipan dan wawancara mendalam dan 2) analisis data termasuk reduksi data, penyajian data, dan penarikan kesimpulan.

\footnotetext{
${ }^{14}$ Sukamto, Kepemimpinan Kiai Dalam Pesantren (Lp3es, 1999).

15 Nana Syaodih Sukmadinata, Metode Penelitian Pendidikan (Bandung: PT Remaja Rosdakarya, 2011).

16 Irawan Irawan and Mahmud Mahmud, "Strategic Management System as The Internationalization Policy of Indonesian Islamic Higher Education," Advances in Social Science, Education and Humanities Research (ASSEHR), Volume 66 1st Yogyakarta International Conference on Educational Management/Administration and Pedagogy (YICEMAP 2017) Volume 66, no. Yicemap (2017): 150-56.

${ }^{17}$ S. Nasution, Metode Research (Penelitian Ilmiah) (Jakarta: PT Bumi Aksara, 2003).
}

Dirasah, Vol. 3, No.2, Agustus 2020 


\section{Hasil Penelitian dan Pembahasan \\ Kepemimpinan Karismatik Kiai di Pondok Pesantren Salafiyah Al-Jawahir}

Menjadi suri tauladan (role model) merupakan karakteristik dari Nabi Muhammad SAW. Hal ini berarti seorang pemimpin harus menjadi contoh yang baik bagi pengikutnya.Seorang pemimpin akan terus dinilai oleh peserta didik, rekan kerja, dan masyarakat luas, baik secara formal maupun informal ${ }^{18}$. KH Mamat Saeful Qodir selaku pimpinan pesantren selalu memberikan contoh yang baik dalam kepemimpinannya, baik dalam memimpin keluarga maupun santrinya.

Berdasarkan hasil penelitian, beberapa informan memberikan informasi tentang sikap suri tauladan dari KH Mamat Saeful Qodir. Menurut Yadi Supriadi, salah satu pengajar di Pondok Pesantren Salafiyah Al-Jawahir, KH Mamat selalu berusaha menjadi contoh yang baik, ia selalu mengajari santrinya berperilaku baik di mana saja, kapan saja, dan dengan siapa saja. Menurutnya, dia selalu sesuai antara ucapan dan tingkah lakunya. Dia merupakan seorang pimpinan pesantren yang menjadi teladan bagi santrinya (Y. Supriadi, wawancara, 3 Desember 2018).

Dalam menjalankan perannya sebagai pimpinan pesantren, KH. Mamat Saeful Qodir menjalankan kepemimpinannya langsung di pesantren. KH Mamat Saeful Qodir menerapkan sistem kepemimpinan demokratis sehingga keputusan dibuat berdasarkan hasil musyawarah dengan dewan pengajar walaupun keputusan akhir tetap ada padanya $^{19}$.

Menurut Dena Lesmana, "KH Mamat selalu memberikan contoh yang baik kepada seluruh santrinya. Menjadi suri tauladan yang baik merupakan akhlak Rasulullah. Jangan mengatakan apa yang tidak kita lakukan" (D. Lesmana, wawancara, 3 Desember 2018). Hal yang sama juga diklarifikasi oleh Bayu Yusdian Maulana yang menyatakan bahwa, "Menjadi contoh yang baik bagi orang lain itu sulit, tapi kita harus selalu berusaha untuk dapat melakukannya karena yang dibutuhkan oleh orang lain adalah bukti nyata, bukan sekedar ucapan belaka, itulah yang pernah dikatakan beliau kepada kita” (B.Y. Maulana, wawancara, 3 Desember 2018).

\section{Budaya Organisasi di Pondok Pesantren Salafiyah Al-Jawahir}

KH. Mamat Saeful Qodir selalu ingin para santri terus belajar dan mau mengajar. Ia ingin murid-muridnya menyampaikan semua ilmu yang dimiliki oleh santri kepada masyarakat. Sehingga santri bisa menjadi pemimpin dan pembimbing di masyarakat.Berdasarkan penelitian yang dilakukan dengan mewawancarai informan, salah satunya adalah Solehudin, ditemukan bahwa, "Pesannya kepada kita sebagai

${ }^{18}$ Jacky Lumby and Marianne Coleman, Leadership and Diversity: Challenging Theory and Practice in Education, Animal Genetics, vol. 39 (London, Thousand Oaks, New Delhi: SAGE Publications, 2007).

${ }^{19}$ Badrudin, Dasar-Dasar Manajemen, I (Bandung: Alfabeta, 2013). 
santri adalah kita harus selalu belajar dan mau mengajar. Beliau tidak menuntut santrinya untuk menjadi seperti beliau. Cita-cita beliau hanya ingin santrinya bisa mengamalkan ajaran agama sehingga santri mempunyai modal dasar dan benteng kekuatan akidah ketika terjun ke masyarakat" (S. Solehudin, wawancara, 3 Desember 2018)

Budaya organisasi di Pondok Pesantren Salafiyah Al-Jawahir diterapkan dalam bentuk kegiatan santri, baik kegiatan harian, mingguan, atau tahunan ${ }^{20}$. Kegiatan harian yang diikuti santri antara lain pembelajaran Nahwu-Sharaf pada pagi hari pukul 05.0007.00, sore hari pukul 15.30-16.30, dan malam hari pukul 20.00-21.00 dengan sistem klasikal,tiap kelas dibimbing oleh satu pengajar. Pada siang hari santri melakukan kegiatan pembelajaran formal di madrasah yang ada di komplek pesantren. Waktu maghrib setelah shalat berjamaah pada pukul 18.00 sampai pukul 20.00 dipakai untuk kegiatan pembacaan dan hafalan Al-Quran.

Kegiatan mingguan yang dilakukan oleh santri adalah setiap Kamis malam pembacaan kitab Al-Barzanji, shalawat, pembacaan yasin, dan pembacaan manakib(kisah keramat Syaikh Abdul Kadir Jailani). Setiap Jum'at malam pengajian kitab Ta'limAl-Muta'allim dan Wasiat Al-Mustafa. Ada juga kegiatan pembelajaran tilawat alqurandan muhadarah yang dilaksanakan setiap Sabtu malam. Setiap hari Minggu santri melaksanakan kegiatan pencak silat. Pada malam harinya santri melaksanakan kegiatan pembacaan istigasah. Selain itu, kegiatan mingguan lainnya adalah pengajian khusus untuk alumni pesantren. Kegiatan pengajian tersebut diisi dengan kajian kitab Tanqih Al-Qaul dan At-Taqriratu As-Sadidah.

Kegiatan yang rutin dilakukan setahun sekali di Pondok Pesantren Salafiyah Al-Jawahirmeliputi kegiatan memperingati Maulid Nabi Muhammad SAW, memperingati Isra Mi'raj Nabi Muhammad SAW, napak tilas ziarah ke makam Walisongo, tahun baru hijriah, dan Idul Adha. Kegiatan Idul adha diisi dengan kegiatan shalat 'id berjamaah, kemudian dilanjutkan dengan pemotongan hewan kurban.

Budaya organisasi yang diterapkan di kalangan santri meliputi pembentukan Risalah (Organisasi Santri Salafiyah) yang merupakan struktur organisasi yang di dalamnya terdapat anggota-anggota yang terdiri dari santri senior yang menjadi pengajar dan santri-santri usia sekolah menengah ${ }^{21}$. Organisasi tersebut langsung di

${ }^{20}$ Ari Prayoga, Jaja Jahari, and Mutiara Fauziah, "MANAJEMEN PROGRAM VOCATIONAL LIFE SKILL PONDOK PESANTREN," J-MPI (Jurnal Manajemen Pendidikan Islam) 4, no. 2 (December 2019): 97-106, https://doi.org/10.18860/jmpi.v4i2.8093; Ari Prayoga and Mohammad Sulhan, "Pesantren Sebagai Penangkal Radikalisme Dan Terorisme" 5, no. 2 (2019): 163-77.

21 Ari Prayoga and Ima Siti Mukarromah, "Kiai Pondok Pesantren Mahasiswa," Madrasa: Journal of Islamic Educational Management 1, no. November (2018): 30-38, https://doi.org/10.32940/mjiem.v1i0.72; Ari Prayoga, "Manajemen Program Pembinaan

Dirasah, Vol. 3, No.2, Agustus 2020 
bawah arahan KH Mamat Saeful Qodir selaku pimpinan pesantren.Dalam struktur organisasi tersebut terdapat ketua yang dipegang oleh santri senior. Ketua tersebut membawahi divisi-divisi yang dikelola oleh santri, yaitu divisi peribadatan, divisi kesehatan, divisi kebersihan, divisi keamanan, divisi absensi, divisi sarana prasarana, dan divisi perairan. Setiap divisi dikelola oleh satu koordinator yang membawahi empat sampai delapan anggota.

\section{Peran Pemimpin Karismatik Kiai dalam Membangun Budaya Organisasi di Pondok Pesantren Salafiyah Al-Jawahir}

Karismatik kepemimpinan kiaimemiliki peran strategis dalam membangun budaya organisasi di pesantren. Kepemimpinan karismatik yang ditemukan di Pondok Pesantren Salafiyah Al-Jawahir antara lain memberikan contoh kepada santri dalam hal disiplin, tanggung jawab, kejujuran, kemandirian, kesederhanaan, semangat, keberanian, dan keadilan. Selain itu, seorang kiai juga menjadi pemimpin dalam hal menjaga jati diri pesantren dan melakukan perannya sebagai mentor pesantren.

Salah satu karakteristik dari kekuatan komunikasi seorang pemimpin adalah keberaniannya untuk mengungkapkan kebenaran bahkan jika itu sangat berisiko. Dia memperlakukan sangat ketat kepada mereka yang melanggar hukum, tetapi sangat lembut dan memaafkan ketika ada sebuah kesalahan yang menyangkut dirinya sendiri. Katakan dan sampaikan kebenaran meskipun itu pahit, begitulah cara dia mengajar santrinya.

KH Mamat Saeful Qodir adalah sosok yang adil, Dia selalu menerapkan prinsip keadilan dalam kehidupan sehari-hari untuk membimbing keluarga dan santrinya. Dia menjadi model keadilan untuk santrinya. Dia selalu tegas menjunjung prinsip keadilan. Ini sesuai dengan pendapat Aang Nurhidayat yang mengatakan bahwa, "KH Mamat Saeful Qodir adalah sosok pemimpin yang adil, ia pasti akan menegur santri yang bertindak salah atau melanggar peraturan" (A. Nurhidayat, wawancara, 4 Desember 2018).

Dalam hal ukhuwahnya, KH Mamat Saeful Qodir adalah seorang ulama yang selalu mengutamakan ukhuwah. Meskipun kadang-kadang memiliki perselisihan dengan orang lain, ia berusaha untuk tetap harmonis dan menjaga ukhuwah selalu terjalin dengan siapa pun. Sebagai tokoh utama dalam memimpin pesantren, ia juga menjadi teladan bagi santri. Dia menerapkan banyak kualitas terpuji yang bisa diambil dan dipraktikkan oleh santri.

Menurut KH Mamat Saeful Qodir salah satu faktor kemerosotan dan kelemahan umat Islam saat ini bukan karena umat Islam malas untuk berpikir, tetapi karena dalam pemikiran beberapa Muslim menjauhkan diri dari ajaran Islam, terpesona oleh ajaran-ajaran di luar Islam (M.S. Qodir, wawancara, 4 Desember 2018). 
Berdasarkan hasil wawancara, menurut Muhammad Arif Faturohman "KH Mamat Saeful Qodir adalah orang yang sangat amanah, dia adalah bukti yang sangat kredibel dan dapat dipercaya sehingga ia ditugaskan untuk memimpin pesantren" (M.A. Faturohman, wawancara, 4 Desember 2018).

\section{Penutup}

Kiai karismatik memiliki peran strategis dalam upaya mengembangkan budaya organisasi di pesantren. Budaya organisasi di Pondok Pesantren Salafiyah Al-Jawahir diterapkan melalui kegiatan santri yang meliputi kegiatan harian, mingguan, dan tahunan. Selain melalui kegiatan tersebut, budaya organisasi juga diterapkan dalam kehidupan pondok melalui pendirian struktur organisasi yang dikelola oleh santri. Kepemimpinan kiai karismatik di Pondok Pesantren Salafiyah Al-Jawahir mengimplementasikan sistem kepemimpinan demokratis dalam menjalankan pesantren sehingga keputusan dibuat berdasarkan hasil musyawarah dengan dewan pengajar, namun keputusan akhir tetap ada pada pimpinan.Kiai menjadi panutan dalam kehidupan masyarakat di dalam dan luar pesantren.

\section{Daftar Pustaka}

Badrudin. Dasar-Dasar Manajemen. I. Bandung: Alfabeta, 2013.

Dhofier, Zamakhsyari. "THE PESANTREN TRADITION: A Study of the Role of the Kyai in the Maintenance of the Traditional Ideology of Islam in Java." THE AUSTRALIAN NATIONAL UNIVERSITY, 1998.

Hefner, Robert W., ed. Making Modern Muslims: The Politics of Islamic Education in Southeast Asia. Honolulu: University of Hawai'i Press, 2009.

Hidayat, Mansur. "Model Komunikasi Kyai Dengan Santri Di Pesantren." Jurnal ASPIKOM 2, no. 6 (2017): 385. https://doi.org/10.24329/aspikom.v2i6.89.

Hiebert, Murray, and Bruce Klatt. The Encyclopedia of Leadership: S Practical Guide to Popular Leadership Theories and Techniques. New York: McGraw-Hill, 2001.

Irawan, Irawan, and Mahmud Mahmud. "Strategic Management System as The Internationalization Policy of Indonesian Islamic Higher Education." Advances in Social Science, Education and Humanities Research (ASSEHR), Volume 66 1st Yogyakarta International Conference on Educational Management/Administration and Pedagogy (YICEMAP 2017) Volume 66, no. Yicemap (2017): 150-56.

Kavanagh, Marie H., and Neal M. Ashkanasy. "The Impact of Leadership and Change Management Strategy on Organizational Culture and Individual Acceptance of 
Change during a Merger." British Journal of Management 17, no. SUPPL. 1 (2006). https://doi.org/10.1111/j.1467-8551.2006.00480.x.

Kessler, Eric H. Management Theory in Action: Real-World Lessons for Walking the Talk. New York: PALGRAVE MACMILLAN, 2010.

Lumby, Jacky, and Marianne Coleman. Leadership and Diversity: Challenging Theory and Practice in Education. Animal Genetics. Vol. 39. London, Thousand Oaks, New Delhi: SAGE Publications, 2007.

Lussier, Robert N., and Christopher F. Achua. LEADERSHIP Theory, Application, \& Skill Development. 4th ed. OH: Cengage Learning, 2010.

Muflichah, Siti. "The Charisma Leadership Style of Kyai Haji Arwani Amin The Founder of Yanbuul Quran Pesantren, Kudus." Journal of Islamic Civilization in Southeast 03, no. 01 (2014): 61-81. https://doi.org/10.24252/JICSA.V3I1.774.

Nasution, S. Metode Research (Penelitian Ilmiah). Jakarta: PT Bumi Aksara, 2003.

P.A.Duignan, and R.J.S.Macpherson, eds. Educative Leadership: A Practical Theory for New Administrators and Managers. Bristol: The Falmer Press, Taylor \& Francis Inc., 2004.

Prayoga, Ari. "Manajemen Program Pembinaan Akhlak Karimah Peserta Didik Melalui Ekstrakurikuler.” Jurnal Isema : Islamic Educational Management 04, no. 01 (2019): 93-104. https://doi.org/10.15575/isema.v4i1.5142.

Prayoga, Ari, Jaja Jahari, and Mutiara Fauziah. "MANAJEMEN PROGRAM VOCATIONAL LIFE SKILL PONDOK PESANTREN.” J-MPI (Jurnal Manajemen Pendidikan Islam) 4, no. 2 (December 2019): 97-106. https://doi.org/10.18860/jmpi.v4i2.8093.

Prayoga, Ari, and Ima Siti Mukarromah. "Kiai Pondok Pesantren Mahasiswa." Madrasa: Journal of Islamic Educational Management 1, no. November (2018): 30-38. https://doi.org/10.32940/mjiem.v1i0.72.

Prayoga, Ari, and Mohammad Sulhan. "Pesantren Sebagai Penangkal Radikalisme Dan Terorisme" 5, no. 2 (2019): 163-77.

Siregar, Ferry Muhammadsyah, Nur Kholis Setiawan, and Robert Setio. "Religious Leader and Charismatic Leadership in Indonesia: The Role of Kyai in Pesantren in Java." Kawistara 3, no. 2 (2013): 117-226.

Sukamto. Kepemimpinan Kiai Dalam Pesantren. Lp3es, 1999.

Sukmadinata, Nana Syaodih. Metode Penelitian Pendidikan. Bandung: PT Remaja Rosdakarya, 2011. 
Tan, Charlene. Islamic Education and Indoctrination: The Case in Indonesia. New York: Routledge, 2011.

Copyright (C) 2020Journal Dirasah: Vol. 3, No.2, Agustut 2020, p-ISSN: 2615-0212, e-ISSN; 2621-2838

Copyright rests with the authors

Copyright of Jurnal Dirasah is the property of Jurnal Dirasah and its content may not be copied oremailed to multiple sites or posted to a listserv without the copyright holder's express writtenpermission. However, users may print, download, or email articles for individual use. https://ejournal.iaifa.ac.id/index.php/dirasah 